\title{
META-AVALIAÇÃO DE POLÍTICAS DE CIÊNCIA, TECNOLOGIA E INOVAÇÃO NA AMÉRICA LATINA
}

\author{
Lissa V. Pinheiro*, Adriana Bin, Rafaela M. de Andrade.
}

\begin{abstract}
Resumo
O propósito desta pesquisa foi sistematizar, caracterizar e analisar a prática da avaliação de políticas de Ciência, Tecnologia e Inovação (CTI) na América Latina, com ênfase em Argentina, Brasil, Chile, Colômbia, México e Uruguai. Para tal, a pesquisa valeu-se de uma metodologia já estabelecida no âmbito de uma iniciativa internacional mais ampla: Science and Innovation Policy Evaluations Repository (SIPER) coordenada pelo Manchester Institute of Innovation Research. Os resultados indicam alguns padrões na forma com que tais avaliações vêm sendo executadas e de que há um crescente movimento de institucionalização da avaliação de políticas de CTI na região.
\end{abstract}

\section{Palavras-chave:}

Meta-avaliação, Políticas de CTI, América Latina.

\section{Introdução}

Há, nas últimas décadas, um crescente reconhecimento da importância das políticas de CTI, dado seu potencial em contribuir para o desenvolvimento econômico e social dos países ${ }^{1}$. Mensurar a efetividade destas políticas por meio de exercícios de avaliação é uma atividade que vêm sendo realizada em diversos países, seja para compreender seus resultados e impactos e prestar contas à sociedade, seja para aprimorar efeitos desejáveis e desenhar políticas cada vez mais efetivas².

Compreender o papel das avaliações de políticas de CTI é essencial, na medida em que, um bom planejamento e uma boa avaliação caminham lado a lado. Tendo isso em vista, tornam-se relevantes os esforços de metaavaliação, que podem ser compreendidos como a avaliação da avaliação $^{3}$, ou ainda, como estudos orientados à mensuração da qualidade de uma avaliação e atribuição de juízo de valor a ela, baseando-se em critérios do que é considerado uma "boa" avaliação".

Neste contexto, a presente pesquisa tem como objetivo sistematizar, caracterizar e analisar a prática da avaliação de políticas de CTI, com ênfase em países latino-americanos.

\section{Resultados e Discussão}

A presente pesquisa é fruto de uma parceria com ao projeto SIPER, que se destaca como uma iniciativa européia no campo da meta-avaliação, orientada à construção de um repositório online de avaliações de políticas de CTI. Tendo em vista tal parceria, o projeto organizou-se em três etapas: (1) Identificação e coleta das avaliações de políticas de CTI na América Latina; (2) Classificação das avaliações e das políticas avaliadas com base em um questionário estruturado; (3) Análise das informações obtidas para discutir o estado-da-arte da avalição de políticas da região.

As avaliações encontradas foram caracterizadas segundo as características: beneficiários da política, como o benefício é concedido, objetivos da política, quem realizou a avaliação, o timing da avaliação, objetivos da avaliação, aspectos básicos que a avaliação examinou (resultados, impactos, adicionalidade etc), design da avaliação, métodos de coleta de dados, métodos de análise de dados e questões de qualidade.
A fase de coletas recolheu (até o presente momento) 128 documentos de avaliação (Tabela 1) dos quais 73 destes já foram classificados e analisados.

Tabela 1. Avaliações coletadas segundo os países.

\begin{tabular}{|l|c|c|}
\hline \multicolumn{1}{|c|}{ País } & Documentos & Classificações \\
\hline Argentina & 26 & 24 \\
\hline Brasil & 32 & 4 \\
\hline Chile & 20 & 10 \\
\hline Colômbia & 18 & 15 \\
\hline México & 18 & 17 \\
\hline Uruguai & 14 & 3 \\
\hline
\end{tabular}

As análises dessas avaliações demonstrou que há predominância de avaliações de políticas de CTI voltadas a ampliação e melhoria das atividades de pesquisa orientadas às empresas, por meio de suporte financeiro direto ou indireto. São em sua maioria avaliações realizadas durante a implementação da medida (ex post intermediário), conduzidas por equipes externas à política ou mistas, e avaliam os efeitos e resultados da medida (caráter somativo). Há ênfase no uso de indicadores econômicos e, em menor grau, científicos e tecnológicos e sociais para mensuração de resultados, e em menor frequência dos casos, de impactos. É predominante o design quase-experimentais e não experimentais, que utilizam base de dados secundários, assim como dados primários coletados por surveys e entrevistas. Empregam-se majoritariamente análises econométricas e estatísticas descritivas.

\section{Conclusões}

Essas análises permitiram identificar um processo de institucionalização da prática de avaliação de CTI na América Latina, seguindo a tendência internacional já reconhecida.No entanto, poucas variações nos desenhos metodológicos e indicadores empregados, evidenciando a necessidade de avanços significativos neste campo.

1SALTER, A.J.; MARTIN, B.R. The economic benefits of publicly funded basic research: a critical review. Research Policy, Brighton,v.30,n.3,p.509-532, 2001. ${ }^{2}$ EDLER, J. et al. The practice of evaluation in innovation policy in Europe Research Evaluation, Londres, v.21, n.3, p. 167-182, dez.2012.

${ }^{3}$ SCRIVEN, M. Meta-Evaluation Revisited. Journal of MultiDisciplinary Evaluation, Michigan, v.6, n.11, p. 3-8, fev.2009.

${ }^{4}$ STUFFLEBEAM, D. L. The Meta evaluation Imperative. American Journal of Evaluation, Michigan, v. 22, n. 2, p. 183-209, jun.2001. 